\title{
Extrinsic Optical Fiber Pressure Sensor Based on F-P Cavity
}

\author{
Jianxian Cai*, Gang Wang, Yanxiong Wu, Zhitao Gao, Zhongchao Qiu \\ College of Electronic Science and Control Engineering, Institute of Disaster Prevention, Langfang 065201, China
}

Corresponding Author Email: jianxian.cai@hotmail.com

\author{
https://doi.org/10.18280/i2m.190106
}

Received: 19 August 2019

Accepted: 1 November 2019

\section{Keywords:}

in-situ stress monitoring, extrinsic opticalfiber pressure sensor based on F-P cavity, sensitive diaphragm, lightning strike

\begin{abstract}
Aiming at the problems of the in-situ stress monitoring sensor such as susceptibility to lightning strikes and low accuracy, this paper attempts to design one extrinsic pressure sensor based on the optical fiber sensing technology and F-P interferometer. To this end, it first introduces the structural design of the sensor, which is mainly composed of sensitive diaphragm, single-mode fiber and ceramic ring. The use of silver-plated diaphragms in the air cavity can increase the light reflectivity, thereby improving the monitoring accuracy; the insulating anti-electromagnetic interference material can make the sensor less susceptible to lightning strikes and reduce the risk of damage to the sensor due to lightning strikes. Then, the ANSYS simulation software was used to statically analyze the silverplated diaphragm of the sensor, and obtain the ideal radius and thickness values of the silver-plated diaphragm. Furthermore, to verify the accuracy and lightning protection performance of the extrinsic fiber pressure sensor based on F-P cavity in actual stress measurement, an in-situ stress monitoring experiment platform and a simulated lightning strike experiment platform were built. The pressure and temperature calibration experiments and sensor stress loading simulation showed that the sensor has a cavity length change sensitivity of $1677 \mathrm{~nm} / \mathrm{MPa}$ within $0-10 \mathrm{MPa}$ and a stress measurement resolution of $60 \mathrm{~Pa}$; compared with the common fiber grating method for in-situ stress measurement, the monitoring accuracy of the designed sensor has improved about 3 times; the lightning strike experiment found by using a lightning surge generator that the designed sensor has a stable operating and anti-lightning performance under the test voltage of $0.5 \mathrm{kV}$. The research findings shed light on the further study of F-P cavity-based extrinsic fiber pressure sensor.
\end{abstract}

\section{INTRODUCTION}

In-situ stress refers to a natural force that objectively exists in the crustal rock body and is not disturbed by engineering. It causes the crustal rock body to deform, fracture, fold and even earthquake [1-3]. With the continuous increase of China's mining, tunnels, water conservancy and hydropower, geothermal energy development, nuclear waste disposal and other projects, such problems as rock burst, roadway deformation, and high slope instability have become increasingly prominent. In addition, China is one of the countries with the strongest tectonic activities in the world today. Inland earthquakes, landslides and other geological disasters occur frequently [4]. Therefore, the in-situ stress monitoring of the crustal stress state cannot only serve the engineering construction of various rock masses, but also provide an important scientific basis for geodynamic research, fault activity research and geological disaster early warning research [5-7]. It's achieved by measuring the dynamic change law of stress with time, i.e., through the sensor element, measure and record the stress change of the crustal rock mass, and then obtain the stress state of key structural parts. This can also provide stress boundary conditions for the active fracture in the fields of dynamics study, inversion of crustal stress field, geological hazard research and prevention, earthquake prediction, and urban construction, etc. [8-9]. Monitoring accuracy is one of the core issues in the in-situ stress monitoring. On the one hand, the monitoring accuracy is affected by the objective factors such as temperature, air pressure, ground noise, natural and human factors interference to a certain extent, and the choice of sensor materials (density, Poisson's ratio); on the other hand, the in-situ stress monitoring sensors are generally traditional electrical instruments, and easily damaged by lightning strikes during work, which affects the normal in-situ stress monitoring. Therefore, it's very necessary to study the high-precision and lightning protection sensors for in-situ stress monitoring, which has become a key issue to be solved urgently.

The monitoring technology and research on in-situ stress in China began in the 1960 s, and developed rapidly in the following decades. At present, the relative monitoring technology used for crustal rock stress mainly includes GPS monitoring technology [10-12], Interferometric Synthetic Aperture Radar (InSAR) technology [13-15], and borehole strain observation technology [16-17]. Both GPS and InSAR methods can not only measure the displacement of the monitoring point in the monitoring time interval, but also derive the corresponding strain using the equation, but such methods are easily affected by the natural environment and human factors in the actual measurement, with low measurement accuracy. The borehole strain observation instruments mainly include volumetric strain gauges, capacitive strain gauges and borehole multi-component observers, etc.; the borehole strain observation technology is 
to install the measurement instruments under the boreholes from tens to hundreds of meters in the bedrock, and measure the internal stress state of the bottom layer [18-19] when the sensor is highly coupled with the rock mass. Considering the selection of the shell material is a factor affecting the measurement accuracy, this monitoring method avoids the effects of ground noise, temperature, and human interference. However, all above use traditional electrical monitoring instruments. They have poor resistance to electromagnetic interference and are easily damaged by lightning strikes, failing to achieve long-distance transmission and collection, so it is difficult to meet the requirements for long-term stable and effective monitoring.

Due to the characteristics of anti-electromagnetic interference, high dielectric strength, and corrosion resistance, etc. of the optical fiber, scholars at home and abroad have begun trying to use its sensing technology in the stress monitoring sensors. Teguedy et al. [20] used Brillouin distributed optical fiber sensor to monitor the stress state of 8.5 meters long concrete composite material. Gao et al. [21] designed a composite optical fiber device in the form of a bow tie for monitoring deep displacement and shear displacement; the measurement accuracy of the sensor is $1 \mathrm{~mm}$ and the maximum measurement range is $40 \mathrm{~mm}$. The application of sensor technology in stress monitoring can help to achieve distribution, anti-electromagnetic interference, anti-lightning, and easy networking, but result in low measurement accuracy, which makes it difficult to meet the needs of high-precision monitoring of in-situ stress.

Aiming at the problems of current stress monitoring instruments such as low accuracy and susceptibility to damage caused by lightning strikes, this paper designs an extrinsic fiber-optical pressure sensor based on optical fiber sensing technology and F-P interferometer. The sensor uses the F-P interference composed of a silver-plated diaphragm and a single-mode fiber to form an air cavity, and the ceramic ring as the cavity wall. The silver-plated diaphragm can improve light reflectivity and then monitoring accuracy. The entire structure is insulated against electromagnetic interference to prevent the damage brought by lightning strikes. Finally, the experiment proves that the extrinsic optical fiber pressure sensor based on F-P cavity can resist electromagnetic interference and lightning strike in the monitoring of in-situ stress, and has high monitoring accuracy.

\section{STRUCTURE DESIGN OF THE EXTRINSIC OPTICAL FIBER PRESSURE SENSOR BASED ON F-P CAVITY}

The designed extrinsic fiber pressure sensor based on F-P cavity is mainly composed of sensitive diaphragm, singlemode fiber and ceramic ring, as shown in Figure 1 (a). According to the working system of this sensor, the light emitted by the light source is vertically incident on the end face of the fiber through the fiber; part of the optical power is reflected by the end face of the conducting fiber, while the remaining optical power reaches the silver-plated sensitive diaphragm after transmission, and is partially reflected inside the diaphragm surface and coupled back into the fiber, so that the reflected light at the end of the fiber interferes with the reflected light at the inner surface of the diaphragm. When the silver-plated sensitive diaphragm is deformed by external pressure, it changes the length of the F-P cavity, causing interference light changes. Through spectral demodulation analysis, the pressure change acting on the silver-plated sensitive diaphragm can be measured. The end face of the optical fiber is coated with a metallic silver film [22]. Silver is a metal with extremely high reflectivity, which can reach $95 \%$. Such a metal film can be prepared with high reflectivity, but it also absorbs light very high, so the absorption of light by this layer of film needs to be considered when preparing a reflective film on the end face of the fiber. The thickness of the film made on the end face of the fiber is about $5 \mathrm{~nm}$; considering a high reflectivity, the metal film made by experiment has the reflectivity of above $90 \%$.

The in-situ stress observation probe is composed of extrinsic fiber pressure sensor based on F-P cavity, and oil pressure cavity etc., as shown in Figure 1 (b). The probe is coupled in a predetermined borehole. With the stress state of the rock mass changing, the oil pressure in the probe also varies. The oil pressure value measured by the extrinsic F-P pressure sensor in the probe is the relative in-situ stress monitoring value.

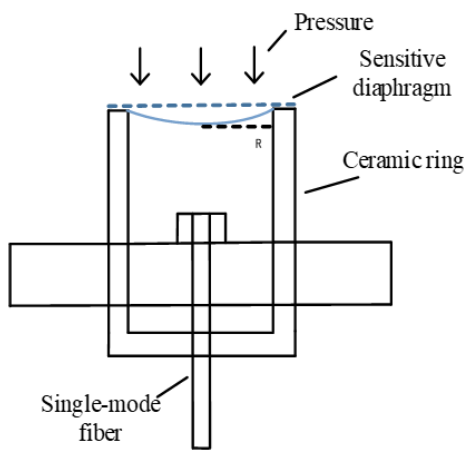

Figure 1(a). Extrinsic fiber f-p pressure sensor structure

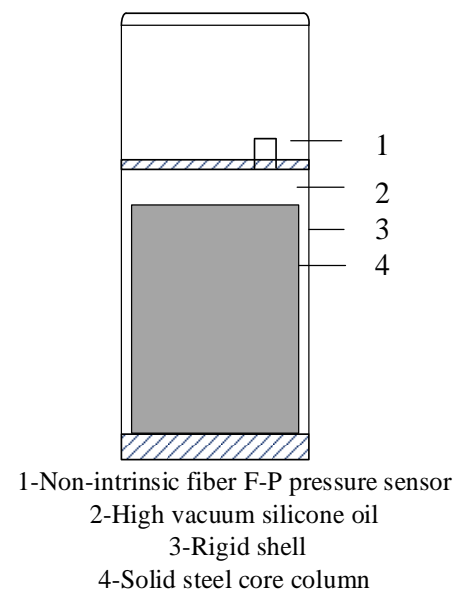

Figure 1(b). Stress observation probe structure

\section{FABRICATION OF EXTRINSIC FIBER PRESSURE SENSOR BASED ON F-P CAVITY}

\subsection{Mechanical analysis of extrinsic fiber pressure sensor based on F-P cavity}

When the in-situ stress acts on the probe, its shell is deformed, the volume changes, and the oil pressure in the shell also changes. Plus, the deformation quantity of the sensitive diaphragm in the extrinsic FP pressure sensor varies. These deformations directly affect the measurement results and 
accuracy. In order to obtain the ideal sensitive diaphragm parameters, the mechanical analysis was performed on mechanical relationship between the stress of the outer shell and the oil pressure in the shell, as well as the deformation of the sensitive diaphragm in the extrinsic F-P cavity-based pressure sensor under oil pressure.

The corresponding relationship between the deformation caused by the force of the shell and the relevant pressure change generated by the silicone oil in the shell can be expressed as:

$$
\Delta P=K_{C} \frac{\Delta V}{V}
$$

where, $\Delta P$ is pressure change of silicone oil in the shell, $\Delta V / V$ is the volume deformation of the rigid shell in the monitoring probe, and $K_{C}$ is the apparent compression modulus of the probe. According to the mechanical design of the probe, take $K_{C}=5000 \mathrm{MPa}$ for calculation.

Based on the principle of elastic mechanics, the relationship between the oil pressure acting on the sensitive diaphragm of the extrinsic pressure sensor and the variable deformation can be expressed as:

$$
\Delta d=\frac{3\left(1-\mu^{2}\right) \Delta p}{16 E h^{3}} \cdot\left(R^{2}-r^{2}\right)^{2}
$$

where, $\Delta d$ is the deformation of the sensitive diaphragm, $r$ is a function of its radius, $\mu$ is the Poisson's ratio of the sensitive diaphragm material, $E$ is the Young's modulus of elasticity of the sensitive diaphragm material, $h$ is the thickness of the sensitive diaphragm, $R$ is the effective pressure-sensing radius, and $\Delta p$ is the pressure difference between the inside and outside of the sensitive diaphragm.

It can be seen from Eq. (1) that the maximum deformation value of the sensitive diaphragm is derived at the center point $(r=0)$ :

$$
\Delta d=\frac{3}{16} \cdot \frac{\left(1-\mu^{2}\right) \Delta p}{E h^{3}} \cdot R^{4}
$$

From Eq. (3), the sensitivity of pressure measurement is proportional to the fourth power of the effective radius of the sensitive diaphragm, and inversely proportional to the third power of its thickness. After the material of the sensitive diaphragm is selected, the pressure measurement sensitivity is determined by the thickness and radius of the sensitive diaphragm.

\subsection{Simulation analysis for sensitive diaphragm of the extrinsic pressure sensor based on F-P cavity}

In order to obtain the deformation value of the sensitive diaphragm under pressure, the static simulation of the sensitive diaphragm was conducted by ANSYS Workbench software, with the parameters setting: The Young's modulus for 200GPa, the Poisson's ratio for 0.3 , and the base material for carbon steel.

With the thickness of the sensitive diaphragm for $1 \mathrm{~mm}$, and the radius for $1 \mathrm{~mm}, 2 \mathrm{~mm}$ and $3 \mathrm{~mm}$ respectively, the simulation calculation was made for the deformation of sensitive diaphragm with the pressure changing; when the radius was increased by 3 times, the diaphragm deformation was expanded by 18 times. The results are shown in Table 1.
Meanwhile, the simulation calculation was also performed with the radius of the sensitive diaphragm for $10.85 \mathrm{~mm}$, and the thickness for $1 \mathrm{~mm}, 2 \mathrm{~mm}$ and $5 \mathrm{~mm}$ respectively; when the thickness increased 5 times, the diaphragm deformation was decreased by 65 times. The results are shown in Table 2. From the data analysis in the table, the deformation caused by the radius and thickness of the sensitive diaphragm was 3: 4, and it's more likely to be affected by the thickness, which corresponds to Eq. (3).

Table 1. Diaphragm of different radii varies with pressure

\begin{tabular}{cccc}
\hline Pressure & $\begin{array}{c}\text { Deformation } \\
\text { (R1) }\end{array}$ & $\begin{array}{c}\text { Deformation } \\
\text { (R2) }\end{array}$ & $\begin{array}{c}\text { Deformation } \\
\text { (R3) }\end{array}$ \\
\hline $2.000 \mathrm{MPa}$ & $0.011 \mu \mathrm{m}$ & $0.057 \mu \mathrm{m}$ & $0.203 \mu \mathrm{m}$ \\
$4.000 \mathrm{MPa}$ & $0.023 \mu \mathrm{m}$ & $0.114 \mu \mathrm{m}$ & $0.406 \mu \mathrm{m}$ \\
$6.000 \mathrm{MPa}$ & $0.034 \mu \mathrm{m}$ & $0.170 \mu \mathrm{m}$ & $0.609 \mu \mathrm{m}$ \\
$8.000 \mathrm{MPa}$ & $0.045 \mu \mathrm{m}$ & $0.227 \mu \mathrm{m}$ & $0.812 \mu \mathrm{m}$ \\
$10.000 \mathrm{MPa}$ & $0.056 \mu \mathrm{m}$ & $0.284 \mu \mathrm{m}$ & $1.016 \mu \mathrm{m}$ \\
\hline
\end{tabular}

Table 2. Diaphragm of different thickness varies with pressure

\begin{tabular}{cccc}
\hline Pressure & $\begin{array}{c}\text { Deformation } \\
\text { (T1) }\end{array}$ & $\begin{array}{c}\text { Deformation } \\
\text { (T2) }\end{array}$ & $\begin{array}{c}\text { Deformation } \\
\text { (T3) }\end{array}$ \\
\hline $2.000 \mathrm{MPa}$ & $23.764 \mu \mathrm{m}$ & $3.352 \mu \mathrm{m}$ & $0.364 \mu \mathrm{m}$ \\
$4.000 \mathrm{MPa}$ & $47.528 \mu \mathrm{m}$ & $6.704 \mu \mathrm{m}$ & $0.728 \mu \mathrm{m}$ \\
$6.000 \mathrm{MPa}$ & $71.292 \mu \mathrm{m}$ & $10.056 \mu \mathrm{m}$ & $1.093 \mu \mathrm{m}$ \\
$8.000 \mathrm{MPa}$ & $95.056 \mu \mathrm{m}$ & $13.408 \mu \mathrm{m}$ & $1.457 \mu \mathrm{m}$ \\
$10.000 \mathrm{MPa}$ & $118.820 \mu \mathrm{m}$ & $16.760 \mu \mathrm{m}$ & $1.821 \mu \mathrm{m}$ \\
\hline
\end{tabular}

From the analysis of Eq. (3) and simulation data, it can be seen that when the material of the sensitive diaphragm is determined, the deformation of the sensitive diaphragm is proportional to the fourth power of the radius and inversely proportional to the third power of the thickness, and the thickness is more likely to affect the deformation of the sensitive diaphragm. The thickness of the sensitive diaphragm determines the bearing capacity. In the selection of the sensitive diaphragm, the thickness was set first, and then the deformation was improved by optimizing the radius of the sensitive diaphragm. According to the simulation data of the sensitive diaphragm, and the measurement range and cavity length setting of the experimental sensor, the simulation was conducted using the ANSYS Workbench software, with the radius of the sensitive diaphragm for $10.85 \mathrm{~mm}$ and the thickness for $2 \mathrm{~mm}$ (Figure 2). The deformation of the sensitive diaphragm was $16.76 \mu \mathrm{m}$ under the pressure of $10 \mathrm{MPa}$.

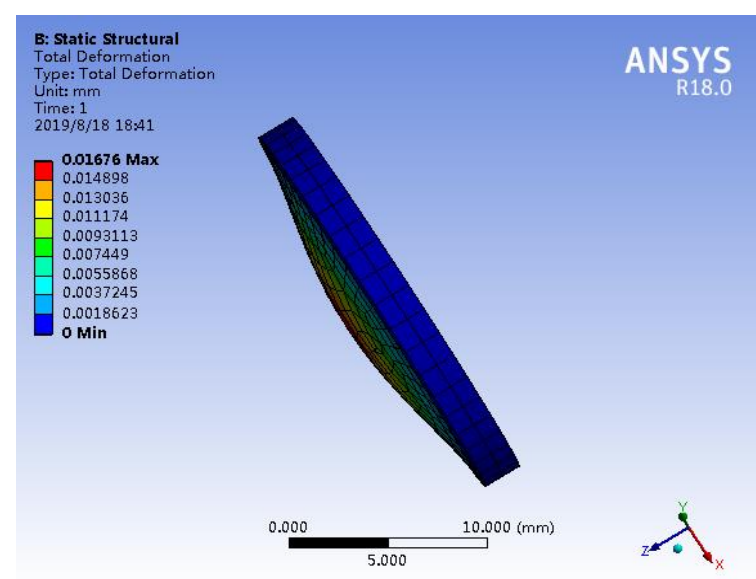

Figure 2. Static simulation of sensitive diaphragm 


\subsection{Fabrication of extrinsic optical fiber pressure sensor based on F-P cavity}

The fabrication of the extrinsic fiber pressure sensor based on F-P cavity was mainly divided into the following steps: In the first step, the single-mode fiber was cut into a flat end face with a cutter, as shown in Figure 3 (a); the single-mode fiber end face is an interference surface, and its vertical flatness affects the interference accuracy; generally, the end angle of the fabricated end surface is less than $0.2^{\circ}$. In the second step, the fabricated single-mode fiber end surface and the sensitive diaphragm were coated with silver, as shown in Figure 3 (b); silver is a metal with very high light reflectivity. Coating a layer of silver film on the two interference surfaces can improve light reflectivity, reduce optical loss, and improve interference accuracy. The third step is to fix the ceramic insert core and silver sensitive diaphragms on the ceramic ring respectively, as shown in Figure 3 (c), because the singlemode fiber is small, and the increase in the contact surface by the ceramic insert core can help to fix. The fourth step is to insert the prepared single-mode fiber into the ceramic insert core, as shown in Figure 3 (d); the end face of the single-mode optical fiber and the silver-plated sensitive diaphragm were separated by tens or hundreds of $\mu \mathrm{m}$ to form an air cavity, which generates light interference in the air cavity. The optical fiber adjusts the length of the air cavity. Figure 4 shows the processed extrinsic F-P-based pressure sensor.

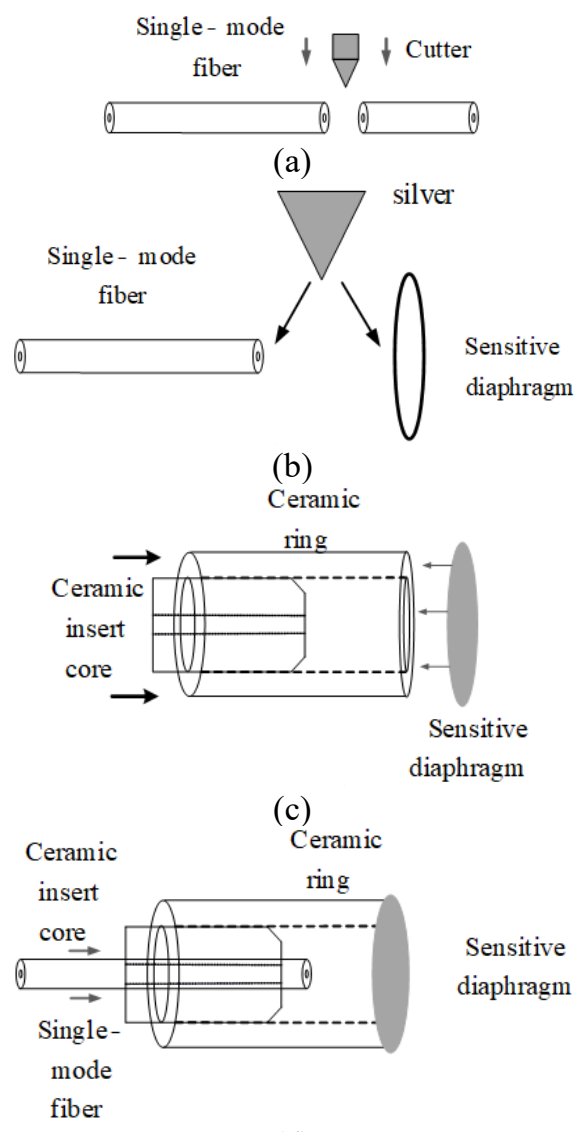

(d)

Figure 3. Sensor manufacturing process

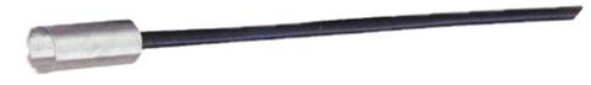

Figure 4. Extrinsic F-P-based pressure sensor

\section{EXPERIMENTAL RESULTS AND ANALYSIS}

\subsection{Signal demodulation system}

Under pressure, the F-P cavity length of the extrinsic fiber pressure sensor based on F-P cavity changed, resulting in a shift in the interference spectrum. The corresponding pressure value was obtained by demodulating the change of the interference spectrum. Figure 5 shows the demodulation system of the extrinsic F-P-based pressure sensor.

In the experiment, the laser light emitted by the light source was transmitted to the sensor through the feeding fiber and the circulator, and the interference spectrum signal that was reflected by the sensor and carried the cavity length information was coupled to the detector through the feeding fiber and the circulator for photoelectric conversion. After the acquisition card sent the measured spectrum data to the computer, the computer performed demodulation calculation. The demodulation of the sensor in the experimental system adopted the method of white light interference wavelength demodulation, and the cavity length value of the sensor was calculated by the minimum mean square error of the interference spectrum and the transfer function of the F-P cavity.

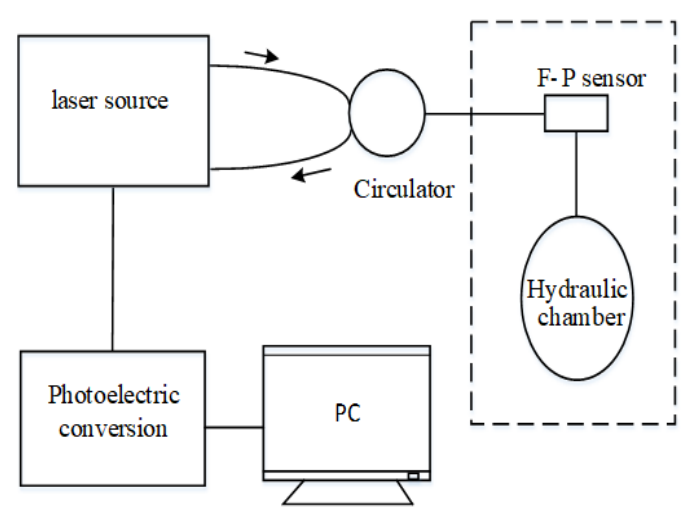

Figure 5. Sensor test system

\subsection{Calibration experiment of extrinsic fiber pressure sensor based on F-P cavity}

\subsubsection{Temperature calibration experiment}

The extrinsic F-P-based pressure sensor works in a borehole with a constant temperature environment, which is less affected by temperature changes. But it's a high-sensitivity monitoring device. Due to the thermo-optic effect and the thermal expansion characteristics of the material itself, the cavity length of the ceramic material will increase with temperature, leading to an error in the measurement of the sensor. Therefore, a temperature calibration experiment was carried out under atmospheric pressure by placing the sensor in a high-low temperature box. The results are shown in Figure 6. With the cavity length of $-20^{\circ}-80^{\circ} \mathrm{C}$ in the sensor, the temperature sensitivity was $0.175 \mathrm{~nm} /{ }^{\circ} \mathrm{C}$, which indicates good temperature stability. During the actual measurement of the extrinsic pressure sensor, both the pressure and temperature caused the cavity length change. Through the temperature calibration experiment, the temperature sensitivity coefficient of the extrinsic FP pressure sensor was obtained. Furthermore, the temperature compensation for the F-P pressure sensor was made under pressure loading to remove the error caused by the temperature. 


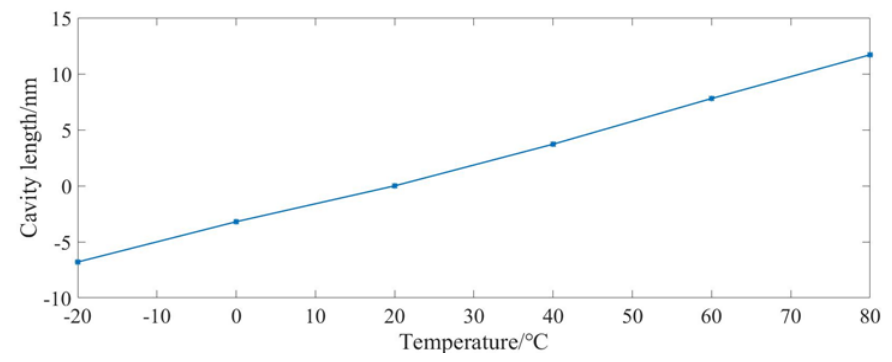

Figure 6. Temperature curve of cavity length

Let the changes in cavity length of the intrinsic F-P pressure sensor caused by ambient temperature $\Delta T$ be $\Delta S$, and the changes in cavity length during pressure loading be $S$, then the cavity length $S_{P}$ of the sensor with only the pressure changed is shown as:

$$
S_{P}=S-\Delta S
$$

\subsubsection{Pressure calibration experiment}

To test the sensitivity of the extrinsic F-P-based pressure sensor, a hydraulic calibration experiment was performed on the sensor at room temperature every $0.001 \mathrm{MPa}$. At room temperature, the initial cavity length of the sensor was 61872.4 $\mathrm{nm}$, and the change in cavity length was $16.77 \mu \mathrm{m}$ under a pressure of $10 \mathrm{MPa}$. The variation curve of cavity length with pressure is shown in Figure 7 . The cavity length fitting curve equation calculated by Matlab was $y-0.0290 x^{2}-$ $1.4177 x+61.6281$, the linearity of the curve was 0.996 , and the sensor sensitivity was $1,677 \mathrm{~nm} / \mathrm{MPa}$.

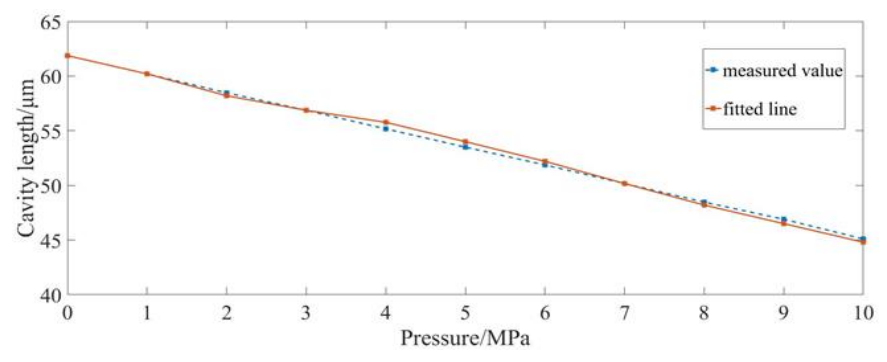

Figure 7. The change curve of sensor cavity length with pressure

\subsection{Simulation experiment for stress loading of extrinsic fiber pressure sensor based on F-P cavity}

To test the in-situ stress monitoring accuracy of extrinsic fiber pressure sensors based on F-P cavity, a stress loading simulation experiment was carried out using an electronic universal experimental press on the concrete body. Figure 8 shows the theoretical model of this device. At room temperature, the encapsulated probe was buried in the concrete body. Assuming that the concrete is homogeneous, imperforate, and isotropic elastomers, pressure was loaded in the vertical direction using an electric press, and the relative stress value of the cement body was measured after wavelength demodulation. The experimental results are shown in Table 3. It can be seen from the results in Table 3, the resolution of cavity length change was $0.1 \mathrm{~nm}$, which is equivalent to the minimum pressure change $60 \mathrm{~Pa}$ that can be measured. According to the mechanical analysis of the probe shell in Eq. (3) $K_{c}=5000 \mathrm{MPa}$, the strain can be reached up to $1.2 \times 10^{-8}$, which is better than the amplitude $1.2 \times 10^{-8}$ of the solid tide. Compare with the accuracy of the general fiber grating in-situ stress monitoring for $10^{-5}$ strain, its monitoring accuracy has been improved by about 3 times.

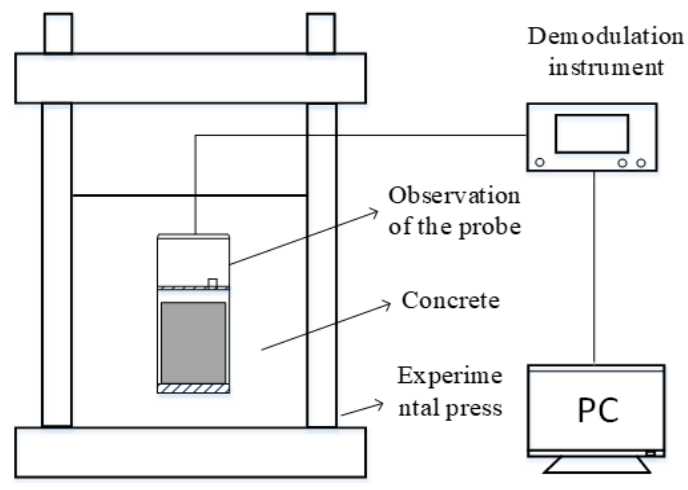

Figure 8. Simulated stress test system

Table 3. Simulated stress test results

\begin{tabular}{ccc}
\hline Simulated stress value & Measured stress & Measured stress change \\
\hline $2.000 \mathrm{MPa}$ & $1.958 \mathrm{MPa}$ & $3283.57 \mathrm{~nm}$ \\
$2.100 \mathrm{MPa}$ & $2.056 \mathrm{MPa}$ & $3447.91 \mathrm{~nm}$ \\
$2.120 \mathrm{MPa}$ & $2.075 \mathrm{MPa}$ & $3479.78 \mathrm{~nm}$ \\
$2.154 \mathrm{MPa}$ & $2.019 \mathrm{MPa}$ & $3385.86 \mathrm{~nm}$ \\
$2.250 \mathrm{MPa}$ & $2.205 \mathrm{MPa}$ & $3697.79 \mathrm{~nm}$ \\
$2.342 \mathrm{MPa}$ & $2.295 \mathrm{MPa}$ & $3848.72 \mathrm{~nm}$ \\
$2.420 \mathrm{MPa}$ & $2.372 \mathrm{MPa}$ & $3977.84 \mathrm{~nm}$ \\
$2.482 \mathrm{MPa}$ & $2.432 \mathrm{MPa}$ & $4078.46 \mathrm{~nm}$ \\
$2.555 \mathrm{MPa}$ & $2.504 \mathrm{MPa}$ & $4199.21 \mathrm{~nm}$ \\
\hline
\end{tabular}

\subsection{Anti-lightning simulation experiment}

In-situ stress monitoring sensors are susceptible to damage by lightning strikes in actual work. To verify the anti-lightning performance of extrinsic fiber pressure sensor based on F-P cavity, simulated lightning strike experiments were carried out. The sensor was fixed on the anti-static plate without load. The voltage generated by the lightning surge generator acted on the pressure sensor through the sensor head, and the measurement was performed at $0 \mathrm{~V}, 12 \mathrm{~V}, 1 \mathrm{KV}$ and $5 \mathrm{KV}$. The experimental results are shown in Table 4.

Table 4. Simulated lightning strike test results

\begin{tabular}{|c|c|c|c|c|}
\hline $\begin{array}{l}\text { No voltage } \\
\text { cavity } \\
\text { length }\end{array}$ & $\begin{array}{c}\text { OV voltage } \\
\text { cavity } \\
\text { length }\end{array}$ & $\begin{array}{l}\text { 12V voltage } \\
\text { cavity } \\
\text { length }\end{array}$ & $\begin{array}{c}1000 \mathrm{~V} \\
\text { voltage } \\
\text { cavity length }\end{array}$ & $\begin{array}{c}5000 \mathrm{~V} \\
\text { voltage } \\
\text { cavity length }\end{array}$ \\
\hline
\end{tabular}

$61872.43 \mathrm{~nm} 61870.68 \mathrm{~nm} 61870.71 \mathrm{~nm} 61870.73 \mathrm{~nm} 61870.69 \mathrm{~nm}$ $61872.39 \mathrm{~nm} 61870.70 \mathrm{~nm} 61870.74 \mathrm{~nm} 61870.75 \mathrm{~nm} \quad 61870.72 \mathrm{~nm}$ $61872.41 \mathrm{~nm} 61870.72 \mathrm{~nm} 61870.69 \mathrm{~nm} 61870.72 \mathrm{~nm} \quad 61870.68 \mathrm{~nm}$ $61872.40 \mathrm{~nm} 61870.71 \mathrm{~nm} 61870.70 \mathrm{~nm} 61870.69 \mathrm{~nm} \quad 61870.70 \mathrm{~nm}$ $61872.38 \mathrm{~nm} 61870.68 \mathrm{~nm} 61870.73 \mathrm{~nm} 61870.71 \mathrm{~nm} \quad 61870.71 \mathrm{~nm}$

It can be seen from Table 4 that the sensor has a cavity length of 61872.4 under no load. When $0 \mathrm{~V}, 12 \mathrm{~V}, 1 \mathrm{kV}$ and $5 \mathrm{kV}$ voltages generated by the sensor tip of the lightning surge generator acted on the sensor, the upper cavity length was all 61870.7 , the cavity length changed about $1.7 \mathrm{~nm}$, the corresponding pressure value was $1 \mathrm{KPa}$, and the stability was $99.99 \%$. The sensor is consistent with the change in cavity length when it's loaded with $0 \mathrm{~V}$ voltage and $5 \mathrm{kV}$ voltage, 
which indicates that the F-P cavity-based extrinsic fiber pressure sensor made of insulating anti-electromagnetic interference material is also insulated in actual use and has anti-lightning performance.

\section{CONCLUSIONS}

In view of the problems of the in-situ stress monitoring sensor such as susceptibility to lightning strikes and low accuracy, this paper attempts to design an extrinsic pressure sensor based on the optical fiber sensing technology and F-P interferometer. The pressure sensor has the following characteristics: (1) Use the insulation anti-electromagnetic interference material; an anti-lightning experiment was carried out by using a lightning surge generator to simulate induction lightning, and the experimental results showed that the designed sensor has stable performance and anti-lightning performance at the test voltage of $5 \mathrm{kV}$. (2) The F-P cavity of the sensor adopts silver-plated end face, which can improve the light reflectivity and the monitoring accuracy. Finally, an experimental platform for in-situ stress monitoring was built to test the performance of the designed sensor. Through pressure and temperature calibration experiments and sensor stress loading simulation experiments, it's found that the sensitivity of the F-P cavity length change of the sensor within $0-10 \mathrm{MPa}$ was $1,677 \mathrm{~nm} / \mathrm{MPa}$, and the stress measurement resolution was $60 \mathrm{~Pa}$. This indicates that compared with the common method fiber grating measuring, the monitoring accuracy of the designed sensor has improved by about 3 times.

\section{ACKNOWLEDGMENTS}

This work was supported by The National Key Research and Development Programme of China (Grant No. 2018YFC1503801), the Special Fund of Fundamental Scientific Research Business Expense for Higher School of Central Government (project for creation teams no. ZY20180111), and the Fundamental Research Funds for the Central Universities (ZY20180112).

\section{REFERENCES}

[1] Konstantinou, K.I., Mouslopoulou, V., Liang, W.T., Heidbach, O., Oncken, O., Suppe, J. (2017). Present-day crustal stress field in Greece inferred from regional-scale damped inversion of earthquake focal mechanisms. Journal of Geophysical Research: Solid Earth, 122(1): 506-523. https://doi.org/10.1002/2016JB013272

[2] Mescua, J.F., Barrionuevo, M., Giambiagi, L., Suriano, J., Spagnotto, S., Stahlschmidt, E., de la Cal, H., Soto, J. Mazzitelli, M. (2019). Stress field and active faults in the orogenic front of the Andes in the Malarguie fold-andthrust belt $\left(35^{\circ}-36^{\circ} \mathrm{S}\right)$. Tectonophysics, 766: 179-193. https://doi.org/10.1016/j.tecto.2019.06.003

[3] Houlie, N., Woessner, J., Giardini, D., Rothacher, M. (2018). Lithosphere strain rate and stress field orientations near the Alpine arc in Switzerland. Scientific Reports, 8(1): 1-14. https://doi.org/10.1038/s41598-01820253-z

[4] Pang, Y., Zhang, H., Cheng, H., Shi, Y., Fang, C., Luan, X., Chen, S., Li, Y., Hao, M. (2020). The modulation of groundwater exploitation on crustal stress in the North China Plain, and its implications on seismicity. Journal of Asian Earth Sciences, 189: 104141. https://doi.org/10.1016/j.jseaes.2019.104141

[5] Baselga, S. (2020). A combined estimator using TEC and b-value for large earthquake prediction. Acta Geodaetica et Geophysica, 55(1): 63-82. https://doi.org/10.1007/s40328-019-00281-5

[6] Majhi, S.K., Hossain, S.S., Padhi, T. (2020). MFOFLANN: moth flame optimized functional link artificial neural network for prediction of earthquake magnitude. Evolving Systems, 11(1): 45-63. https://doi.org/10.1007/s12530-019-09293-6

[7] Kodera, Y. (2019). An Earthquake early warning method based on Huygens principle: robust ground motion prediction using various localized distance-attenuation models. Journal of Geophysical Research: Solid Earth, 124(12): https://doi.org/10.1029/2019JB017862

[8] Onate, C.A. (2016). Bound state solutions of the SchrÖdinger equation with second PÖschl-Teller like potential model and the vibrational partition function, mean energy and mean free energy. Chinese Journal of Physics, 54(2): 165-174. https://doi.org/10.1016/j.cjph.2016.04.001

[9] Chetchotisak, P., Arjsri, E., Teerawong, J. (2020). Strutand-tie model for shear strength prediction of RC exterior beam-column joints under seismic loading. Bulletin of Earthquake Engineering, 18(4): 1525-1546. https://doi.org/10.1007/s10518-019-00756-4

[10] Kaloop, M.R., Hussan, M., Kim, D. (2019). Time-series analysis of GPS measurements for long-span bridge movements using wavelet and model prediction techniques. Advances in Space Research, 63(11): 35053521. https://doi.org/10.1016/j.asr.2019.02.027

[11] Ocalan, T., Erdogan, B., Tunalioglu, N. (2013). Análise dos serviços online que empregam as técnicas dos posicionamentos GPS por ponto preciso e relativo. Boletim de Ciências Geodésicas, 19(2): 191-207. https://doi.org/10.1590/S1982-21702013000200003

[12] Vilayev, A.V., Zhantayev, Z.S., Bibosinov, A.Z. (2017). Monitoring crustal movements in northern Tianshan Mountain based on GPS technology. Geodesy and Geodynamics, $\quad 8(3)$ : $155-159$. https://doi.org/10.1016/j.geog.2017.03.006

[13] Suresh, D., Yarrakula, K. (2018). InSAR based deformation mapping of earthquake using Sentinel 1A imagery. Geocarto International, 35(5): 559-568. https://doi.org/10.1080/10106049.2018.1544289

[14] Wasowski, J., Pisano, L. (2020). Long-term InSAR, borehole inclinometer, and rainfall records provide insight into the mechanism and activity patterns of an extremely slow urbanized landslide. Landslides, 17(2): 445-457. https://doi.org/10.1007/s10346-019-01276-7

[15] Thapa, S., Chatterjee, R.S., Singh, K.B., Kumar, D. (2016). Land subsidence monitoring using PS-InSAR technique for 1-band Sar data. International Archives of the Photogrammetry, Remote Sensing \& Spatial Information Sciences, 40(B7): 995-997. https://doi.org/10.5194/isprs-archives-XLI-B7-9952016

[16] Jia, Y., Gan, W., Li, J., Zhu, C., Yin, H., Lu, S., Ju, J. (2019). Effect of pumping on borehole component strain and its mechanism in Tai'an seismic station. Journal of 
Seismology,

41(6):

$1429-1443$

https://doi.org/10.3969/j.issn.0253-4967.2019.06.008

[17] Gehne, S., Benson, P.M. (2019). Permeability enhancement through hydraulic fracturing: laboratory measurements combining a 3D printed jacket and pore fluid over-pressure. Scientific Reports, 9(1): 12573. https://doi.org/10.1038/s41598-019-49093-1

[18] Currenti, G., Bonaccorso, A. (2019). Cyclic magma recharge pulses detected by high-precision strainmeter data: the case of 2017 inter-eruptive activity at Etna volcano. Scientific Reports, 9(1): 7553. https://doi.org/10.1038/s41598-019-44066-w

[19] Itaba, S. (2018). Rapid estimation of the moment magnitude of the 2011 Tohoku-Oki earthquake (Mw 9.0) from static strain changes. Earth, Planets and Space, 70(1): 124. https://doi.org/10.1186/s40623-018-0894-5
[20] Teguedy, M.C., Joly-Lapalice, C., Sorelli, L., Conciatori, D. (2019). Optical fiber sensors implementation for monitoring the early-age behavior of full-scale TimberConcrete Composite slabs. Construction and Building Materials, 226: 564-578. https://doi.org/10.1016/j.conbuildmat.2019.07.294

[21] Gao, C., Liu, B., Guo, Y., Zhu, Z., Liu, P., Zheng, Y., Liu, H. (2017). A composite optical fiber transduser for landslide monitoring. ACTA PHOTONICA SINICA, 46(8): 149-155. https://doi.org/10.3788/gzxb20174608.0812003

[22] Brunner-Schwer, C., Petrat, T., Graf, B., Rethmeier, M. (2019). Highspeed-plasma-laser-cladding of thin wear resistance coatings: A process approach as a hybrid metal deposition-technology. Vacuum, 166: 123-126. https://doi.org/10.1016/j.vacuum.2019.05.003 